KONRAD J. SCHÖNBORN and SUSANNE BÖGEHOLZ

\title{
KNOWLEDGE TRANSFER IN BIOLOGY AND TRANSLATION ACROSS EXTERNAL REPRESENTATIONS: EXPERTS' VIEWS AND CHALLENGES FOR LEARNING
}

\author{
Received: 30 October 2007; Accepted: 13 January 2009
}

\begin{abstract}
Recent curriculum reform promotes core competencies such as desired 'content knowledge' and 'communication' for meaningful learning in biology. Understanding in biology is demonstrated when pupils can apply acquired knowledge to new tasks. This process requires the transfer of knowledge and the subordinate process of translation across external representations. This study sought ten experts' views on the role of transfer and translation processes in biology learning. Qualitative analysis of the responses revealed six expert themes surrounding the potential challenges that learners face, and the required cognitive abilities for transfer and translation processes. Consultation with relevant curriculum documents identified four types of biological knowledge that students are required to develop at the secondary level. The expert themes and the knowledge types exposed were used to determine how pupils might acquire and apply these four types of biological knowledge during learning. Based on the findings, we argue that teaching for understanding in biology necessitates fostering 'horizontal' and 'vertical' transfer (and translation) processes within learners through the integration of knowledge at different levels of biological organization.
\end{abstract}

KEY WORDS: biological knowledge, expert data, external representations, transfer, translation

There has been recent international emphasis on developing competencybased education (Välijärvi, Linnakylä, Kupari, Reinikainen \& Arffman, 2002). In Germany, the 'Bund-Länder-Kommission' (BLK-expertise, 1997) has revealed deficits in the interconnectedness of knowledge in biology curricula and shortfalls in the systematic transfer of knowledge across levels of biological organization. Implementing competencyoriented national standards in biology aims to provide pupils with key conceptual and procedural knowledge for promoting scientific literacy. Biology pupils are expected to acquire knowledge and understanding that is diverse and embedded at different levels of complexity and abstraction; flexibly transfer knowledge during problem-solving; and interpret and

Electronic supplementary material The online version of this article (doi:10.1007/s10763-0099153-3) contains supplementary material, which is available to authorized users.

International Journal of Science and Mathematics Education (2009) 7: 931-955

(c) The Author(s) (2009) This article is published with open access at Springerlink.com 
translate across multiple external representations. Studies indicate that experts' views can provide reliable information on learning, teaching, and curriculum implementation (see e.g., Osborne, Collins, Ratcliffe, Millar \& Duschl, 2003). The objectives of this study were as follows: Firstly, we sought to obtain experts' views on the role of knowledge transfer (and translation across external representations) in biology learning. Secondly, to consult relevant German curriculum documents to identify the types of biological knowledge that students are expected to acquire for biological understanding. Thirdly, to consider how transfer and translation processes could be related to learners' construction and use of the different knowledge types.

\section{TheoreticAl BACKGRound}

Processes of Understanding, Knowledge Transfer, and Translation in Biology Learning

According to Bloom's revised taxonomy of educational objectives (Krathwohl, 2002), to 'understand' is the ability to determine "the meaning of instructional messages, including oral, written, and graphic communication" (p. 215). Perhaps all educators would agree that fostering understanding is the core objective of learning and teaching. Students demonstrate understanding when they are able to connect existing with new knowledge during the (flexible) transfer of knowledge to meet the demands of novel situations (e.g., Mayer, 2002; Salomon \& Perkins, 1989; Spiro, Collins, Thota \& Feltovich, 2003). Hasselhorn \& Mähler (2000) distinguish, for example, between specific and unspecific transfer (transfer of specific content knowledge or skills to new situations versus transfer of strategies or principles to other contexts), positive and negative transfer (facilitating versus inhibiting learning, based on previous experiences) as well as proximal and distal transfer ('small' versus 'large' transfer requirements). Although these accounts are often exhibited as bipolar classifications, we suggest that transfer in specific tasks exists on a continuum spanning between each 'pole'. Another distinction concerns 'horizontal' and 'vertical' transfer (or 'interconnectedness'), terms which are not consistently defined in the literature. For instance, whereas Hasselhorn \& Mähler (2000) describe horizontal transfer as formulating generalizations within the same level of complexity, and vertical transfer at a super-ordinate level, the BLK-expertise (1997) considers horizontal interconnectedness as the cross-linking between biology, chemistry, and physics, while vertical interconnectedness is seen as the cross-linking 
between different levels of biological organization. The German national standards for biology (KMK, 2005) describe 'horizontal' and 'vertical' perspectives in a way similar to the BLK-expertise (1997). Since the hierarchical structure of biological knowledge consists of interconnected elements, building understanding requires both the 'horizontal' application of knowledge in similar situations, as well as the 'vertical' and systematic building of knowledge at increased levels of abstraction (BLKexpertise, 1997).

Bloom's revised taxonomy goes on to suggest that 'understanding' includes the sub-process of 'interpreting'. Interpreting involves the conversion of information from "one form of representation to another" (Mayer, 2002, p. 228). The process of translation often requires the comprehension and conversion of relationships between different external representations (ERs). Biology teaching uses ERs such as diagrams, physical models, micrographs, and dynamic visuals for communicating knowledge to learners. Ainsworth (1999, p. 134) suggests that ERs support learning through three avenues. Firstly, since ERs contain complementary information, they can promote complementary cognitive processes; secondly, one type of ER may constrain the interpretation of another; and thirdly, ERs can stimulate the construction of deeper understanding. It follows that learners are often required to exhibit what Kozma \& Russell (1997) refer to as a representational competence. Since biological knowledge is communicated at different levels of organization (e.g., BLK-expertise, 1997) that include the 'subcellular', 'cellular' or 'organ' level, translation is a necessary process for successful learning (e.g., Tsui \& Treagust, 2003). Moreover, ERs convey biological knowledge in different 'modes of representation' that exist on a continuum (e.g., Schönborn \& Anderson, 2009) that ranges from 'realistic' at the one end to 'abstract' on the other. To successfully interpret the mode of representation, it is necessary for students to be familiar with the visual conventions used in ERs (e.g., Roth, 2002), and to be able to link the ER to the idea that is represented (Ainsworth, 2006; 1999). Therefore, acquiring biological understanding through translation can be a challenging enterprise.

\section{Relationships Between Transfer and Translation}

Contemporary literature often views knowledge transfer and translation as two distinct processes. For example, 'transfer' often describes the cognitive mechanisms concerned with students' use of what they have learned to solve new problems (Mayer \& Wittrock, 1996; Salomon \& 
Perkins, 1989). 'Translation' often describes mechanisms governing the processing, mapping between and moving across ERs (Ainsworth, 1999). Nevertheless, the two processes often share a close cognitive relationship (e.g., Ainsworth, 2006). Since transfer can be stimulated by translating across ERs, interpreting ERs is a process that can promote knowledge transfer (cf. Tsui \& Treagust, 2003). We hereby consider knowledge transfer as a process that may incorporate the process of translation to some extent, depending on the required learning task (e.g., during the interpretation of ERs). Furthermore, we use 'transfer' to denote the application of students' conceptual knowledge rather than other knowledge types. Given that transfer (and translation) processes can foster understanding, we can now frame their relationship with German core competencies for biology education.

\section{German Biology Curriculum Reform—Experts’ Views}

\section{Links Between Transfer and Translation with Knowledge and Communication Competencies}

In response to the results of the PISA study (e.g., PISA-Konsortium Deutschland, 2005), the German Ministry of Culture and Education established a set of national science education standards ('Bildungsstandards' in German). The biology standards were agreed upon at the conference of the Ministries of Education across all German states in 2004 (KMK, 2005). The biology 'Bildungsstandards' outline four key competency areas, namely, content knowledge ('Fachwissen'), communication ('Kommunikation'), scientific inquiry ('Erkenntnisgewinnung') and decision-making ('Bewertung'). The federal states of Germany face the task of operationalizing the national standards into their own biology syllabi. For example, based on the KMK (2005), the Ministry of Education of the federal state of Lower Saxony has designed a core biology curriculum ('Kerncurriculum') for grades 5-10 (10-16 years old) (Nds. Kultusministerium, 2007). The overall mandate expressed by the KMK and subsequent Niedersächsisches Kultusministerium documents is a drive towards competency orientation. One core message of the curriculum documents (KMK, 2005; Nds. Kultusministerium, 2007) is that students should develop interconnected content knowledge (cf. Harms, Mayer, Hammann, Bayrhuber \& Kattmann, 2004). In biology, this is a challenging prospect because the nature of biological knowledge is extensive and communicated at different levels of organization and 
modes of representation. We suggest that the content knowledge ('Fachwissen') competency is closely related to the notion of transfer (Mayer, 2003; Spiro et al., 2003): in order to construct biological understanding, pupils will unavoidably be required to apply biological content knowledge from one situation or context to another. Furthermore, we suggest that the process of translation is closely related to the communication ('Kommunikation') competency: since ERs are often the 'carriers' of biological information, the ability to translate across different ER modes is very much part of a pupil's ability to 'communicate' as an individual who exhibits biological understanding.

\section{The Role of Obtaining Experts' Views on Aspects of Biology Curricula}

Experienced educational researchers and science educators are critical role players that can provide valuable insight into curriculum development and implementation. Such specialists can reflect upon teaching goals and practices in biology, consider research results and, develop legitimate and sustainable goals that go beyond conventional approaches. In gathering expert data, our approach was aligned to that of Rogers, Abell, Lannin, Wang, Musikul, Barker \& Dingman (2007) who have suggested that it is crucial to obtain the viewpoints of those who essentially determine the impact of policies on classroom practice. Work by Häussler \& Hoffmann (2000) on the implementation of German science curricula has also demonstrated the benefit of analyzing experts' responses. In contrast, the 'Relevance of Science Education' (ROSE) study aims to assess learners' interests, attitudes and experiences for informing curriculum development (Schreiner \& Sjöberg, 2004). Choosing to obtain data from learners or educational experts as a means of informing curriculum implementation depends on the specific research objective. For example, one may be interested in collecting information from learners to shed light on motivation and/or prior conceptions, while information from educational experts would be beneficial for obtaining data concerning teaching goals and practice.

\section{Research Questions}

Given the present challenge of implementing national education standards into German biology education, we posed the following research questions: (i) What are experts' views on the nature and role of transfer and translation in learning biology? (ii) What knowledge is necessary for developing biological understanding at the secondary level? (iii) How 
might transfer and translation processes contribute to the development and application of biological knowledge?

\section{Methods}

Our methods involved multiple steps that included obtaining data from experts during interviews, as well as analyzing relevant German curriculum documents.

\section{Expert Participants}

Nine German didactics of biology experts from four federal states and one Dutch expert participated in the study from September 2006 to February 2007. The ten participants (between 41 and 66 years of age) were comprised of five didactics of biology professors and one research associate (with a $\mathrm{PhD}$ in biology didactics) who are all part of biology education research programs, and four senior biology teachers from the state of Lower Saxony, who are (or were) all involved in state or national curriculum development. The six researchers are among the most informed individuals on how pedagogical psychology outcomes relate to biology didactics in Germany. All participants have expertise in the competency areas of 'content knowledge', 'scientific inquiry', and 'communication', while some also have expertise in 'decision-making'. Purposeful sampling (Patton, 1990) was used to select the key researchers and four respected senior biology teachers in Lower Saxony that we felt best suited our research focus. Since it is difficult to define what exactly constitutes an educational 'expert' (e.g., Osborne et al., 2003), we selected experts who could "reflect on their own professional field in the light of a wider context" and who had an "active commitment to the realization of educational goals" (Häussler \& Hoffmann, 2000, p. 691). Each expert has significant knowledge about biology curricula at the secondary level in Germany. The secondary I level ('Sekundarstufe I') covers the educational period from years 5 to 10 , while the secondary II level ('Sekundarstufe II') includes year 11 to 12 (or 13).

\section{Collection of Expert Data}

Each expert participated in one individual interview. During each interview, experts were presented with a printed sheet containing two 'working definitions' for the processes of transfer and translation in biology. The definitions were formulated prior to the study based on an 
analysis of the literature. The working definition for transfer (KMK, 2005; Mayer, 2002; 2003; Spiro et al., 2003) was presented as:

The ability to transfer knowledge from one situation to another. Within this description, we identify two possible types of transfer. 'Horizontal' transfer is the successful application of biological knowledge from one context to another at the same level of biological organization. 'Vertical' transfer is the successful application of biological knowledge from one level of biological organization to another.

The working definition for translation (cf. Ainsworth, 1999; 2006; Kozma \& Russell, 1997; Prain \& Waldrip, 2006) was presented as:

The ability to move across, interpret, and, in a multi-directional manner, link between ERs that represent an underlying biological concept, principle or process at a particular level of biological organization.

The corresponding semi-structured interview protocol included the following items:

Do you think that the constructs of 'translation' and 'knowledge transfer' are important for the learning and teaching of biology at 'Sekundarstufe I und II'?

Based on your expertise, please provide a critique of these definitions. Should the definitions be adjusted in any way?

Based on your experience, please provide what you think are examples of translation and, horizontal and vertical transfer related to learning biology.

Please provide examples of challenges and specific learning difficulties that students face when they have to engage in translation and transfer processes when learning biology.

Each interview lasted 40-60 min. Eight of the interviews were conducted in English, while two experts requested a translator. During the latter, questions were posed in English and translated into German. One of these experts responded in German, while the other responded in English and only asked the translator to translate words and phrases that were difficult to express. All the interviews were audiotaped and fully transcribed verbatim and faithfully. For the interviewee who responded in German, the English responses generated by the translator were treated as the data.

\section{Analysis of Expert Interview Transcripts}

The transcripts were analyzed qualitatively (e.g., Erickson, 1986; Patton, 1990) according to an inductive category development approach (Mayring, 2000) wherein patterns in the data emerged naturally (Glaser \& Strauss, 
1967) and iteratively (e.g., Osborne et al., 2003). The process involved multiple feedback loops in which themes were revised and subsumed resulting in a step-by-step formulation of categories. The formulation of categories was influenced by the content of the interview questions as well as by the presented transfer and translation definitions. We followed the four basic operations outlined by Lincoln \& Guba (1985) and applied in Miles \& Huberman (1994, p. 62) for reflecting upon the themes that emerged from the data and for modifying them where necessary. Firstly, the process of filling in was attributed to reconstructing coherency in the themes as new insights in the data emerged. Secondly, extension allowed for the expansion of previously coded themes in the data. Thirdly, bridging allowed for the merging of previously obtained themes with other categories in the data. Lastly, surfacing allowed for the identification of novel categories that were not exposed during earlier cycles. Overall, these operations resulted in the identification of six expert themes. Both authors discussed the nature and meanings of the themes (and associated expert quotes) that emerged during the analytical process as a way of pursuing interrater reliability. To strive towards ensuring validity of the emergent themes, any disagreements between the researchers were resolved through further discussion (and analysis when required) until consensus was reached concerning the central description of a theme. Furthermore, to strengthen the validity of the themes, we employed the approach of identifying anchor examples in the data (cf. Eigner-Thiel \& Bögeholz, 2004). An anchor example was described as a datum, which we felt effectively illustrated the nature of a particular theme. In this regard, we searched the data for anchor examples of expert quotes, which served to provide evidence for each respective theme (Erickson, 1986).

\section{Analysis of Biology Curriculum Documents}

Two respective German documents containing the national education standards for biology (KMK, 2005) and core biology curriculum for the federal state of Lower Saxony (Nds. Kultusministerium, 2007) were analyzed to identify the types of biological knowledge that secondary level learners are expected to acquire. By 'types' of knowledge, we mean the factual and conceptual groupings that serve to describe core biological discourse. Accordingly, our designation of these knowledge types paralleled the "conceptual knowledge" types characterized by de Jong \& Ferguson-Hessler (1996) as, "static knowledge about facts, concepts, and principles that apply within a certain domain" (p. 107). Our analysis of the two documents consisted of 'unpacking' the content knowledge by 
deducing (e.g., Mayring, 2000) a structural framework. Specifically, this process involved analyzing the scientific vocabulary used to describe elements of biological knowledge. The documents revealed diverse expressions for describing biological knowledge that included words such as 'facts' ('Fakten' in German), 'terms' (Begriffe), 'concepts' (Konzepte), 'principles' (Prinzipien), 'basic concepts' (Basiskonzepte), 'basic knowledge' (Grundwissen), 'fundamental knowledge' (grundlegendes Wissen) and 'cross-linked knowledge' (vernetztes Wissen). Analysis of these descriptions resulted in the identification of groups of embedded biological meaning, which were then developed into four distinct category types of biological knowledge.

\section{FINDINGS}

The results of this study were framed by responding, in turn, to each of the three formulated research questions.

\section{What are Experts' Views on the Nature and Role of Transfer and Translation in Learning Biology?}

Examples of expert interview excerpts drawn from the respective themes, as well as the number of experts that contributed to each theme are used to illustrate our interpretations and reduction of the data (e.g., Eigner-Thiel \& Bögeholz, 2004; Taylor \& Corrigan, 2007).

Theme 1 Transfer in biology requires the multifaceted use and application of knowledge

Analysis of the interview data indicated that five experts placed a strong emphasis on characterizing knowledge transfer in biology as pupils' ability to 'use' or 'apply' knowledge that they have gained in one situation or context to another. For example, consider the following two expert quotes that illustrate this characterization:

I would say that [transfer] ${ }^{1}$ is the ability to use knowledge you acquired in one situation in another situation. So, I think that you should make a distinction between acquisition of knowledge and the application of knowledge. That is essential in transfer [...] You acquire [knowledge] and you can apply it to another situation. (E5, 272-278).

The most important [aspect] of the new curriculum reform is not the details of knowledge, but more [about] the process to get to know [acquire] this knowledge. And to see the 'Anwendung' [application], what your [learners] can do with this knowledge. So, in this way, you need this form of transfer, from one situation to another. (E9, 463-468). 
In addition, the experts also felt that pupils' application of knowledge is a multifaceted and complex process, a view comprehensively demonstrated by the following two interview excerpts obtained from one of the expert participants:

...there are three levels of complexity of transferring knowledge. 'Reproducing', 'reorganizing' and 'transferring'. There are two dimensions [...] if the knowledge is applied to a familiar or unfamiliar context and whether or not that knowledge is applied in a changed or unchanged form. If it's applied in an unchanged form in a familiar context, then it is reproduction. If it's slightly changed in a familiar context, then it is reorganization... Then, we differentiate between close [near] and far transfer in terms of how much [change has] to be made to the knowledge in new contexts. If it has to be restructured in big ways, it is far transfer. (E1, 145-154).

...the theory of course, is that students can never and will never be able to apply or transfer knowledge if they have not been given the chance to do so, at least a couple of times. So, that each time they apply knowledge, that knowledge is modified, and the ability to transfer is facilitated by these slight changes that are made in each situation. (E1, 207-211).

In conjunction with considering transfer as the application of knowledge to new situations, the above quotes capture facets that mirror 'specific' and 'unspecific' transfer as well as 'proximal' and 'distal' transfer discussed by Hasselhorn \& Mähler (2000). The same expert also highlights that students' application of knowledge depends on the requirements of the learning situation and on previous knowledge transfer experiences (cf. Hammann, 2006).

Theme 2 Transfer in biology requires the application of knowledge in horizontal or vertical directions

Consistent with our working definition for transfer, nine experts strongly communicated two possible 'directions' of knowledge application in biology. Horizontal transfer requires applying knowledge from one situation to another at the same level of biological organization, while vertical transfer requires applying knowledge to different levels of biological organization. Horizontal transfer is demonstrated by the following two interview excerpts:

What comes into my mind is $[\ldots]$ in the context of biological membranes $[\ldots]$ the transfer from... the function of the mitochondrial membrane [to] the function of the thylakoid membrane. (E2, 163-168).

Well, if you analyze for example, a certain cell type and you transfer that knowledge to a different cell type, you don't shift levels. (E1, 163-167). 
The above expert thinking attributes horizontal transfer to biologyspecific contexts, an idea that may also complement the pragmatic definition of the BLK-expertise (1997) that focuses on horizontal crosslinking between subjects, rather than within each subject. In contrast, two examples of vertical transfer are exemplified by the following quotes:

So, the basic concept of 'system' [...] includes the different biological organization levels [...] If you have an understanding of this concept [system], that means that you are able to move from different levels of organization. So, you are able to transfer vertically. (E3, 75-81).

Vertical transfer... if you take the example, why you have to breathe, you have a phenomenon that you can see... you have the 'organismic' and 'organ' level, and then you have the 'tissue' level and then you have the level of understanding why you need oxygen. These are three levels [...] different levels to understand breathing, yes. (E10, 254-264).

As part of the required different 'directions' of transfer expressed in this theme, consider the following excerpt concerning the interlinking and connection of knowledge:

...it is more a horizontal conceptualization, that you broaden your concept [at] a certain biological level... if you're vertical, you connect the biological levels, the phenomena on the different levels [...] in German they call it... 'horizontale und vertikale Vernetzung' [horizontal and vertical cross-linking and integration] [...] connecting, interconnecting, interrelating horizontally, so, connecting concepts to other concepts and vertically relating concepts on different [biological] levels. (E5, 253-262).

The expert data above emphasizes that learning biology requires pupils to make integrated connections in each of the horizontal or vertical directions. This supports the notion that if learners are to construct biological knowledge (which may also be available for potential transfer at a later stage), different 'directions' of application are necessary that consist of horizontal and vertical 'Vernetzung' processes.

Theme 3 Horizontal and vertical transfer in biology requires accessing different 'natures' of knowledge

According to three expert participants, the actual nature of the knowledge itself, which learners are required to apply during each of horizontal and vertical transfer is not equivalent. In support of this, consider the following two quotes:

[With horizontal transfer] it is clear that I have knowledge in the one application and I transfer that knowledge to another example. But [with vertical transfer]... is it actually 
transfer of 'biology knowledge' in this [vertical] direction? If I have a cell containing DNA, I have to know about the DNA. If I go up to the phenotype, I can see how a man or woman looks, for instance in albinism. But, for the connection between the DNA and the organism, I need a new [different] knowledge. Perhaps these two transfers [horizontal and vertical] are not equivalent. (E6, 156-164).

Application of knowledge on one level and, application of knowledge between the levels... you cannot apply the knowledge... which is adequate for one level to another level in the same way. (E4, 239-242).

The expert data presented above suggests that performing horizontal transfer is akin to applying transfer elements or principles within one 'common ground' of knowledge while vertical transfer implies an additive connection of distinct knowledge elements or principles with new information (e.g., elements drawn from separate levels of biological organization). Thus, the actual knowledge that is transferred in each direction is of a unique nature.

Theme 4 Translation in biology requires processing and interpreting the external features of an ER

Initially, as part of translating across ERs, learners are required to process the visual elements contained in a single ER (e.g., symbols, conventions, or external features in the case of a physical model). Students' ability to process these visual features was expressed by four experts. For example, consider the following expert quote:

...[pupils] have their knowledge and for example, they have to say, 'what can I see [specifically] on this original picture [of a plant cell]?'[...] [pupils] must be very specific to say, 'I can only see chloroplasts, and I can see the cell wall, but I can't see the vacuoles'. (E10, 104-109).

The quote above suggests that in order to process the features of an ER, students have to associate the visual elements with relevant biological content knowledge. In this regard, another two experts mentioned the following:

...it is necessary to build up an internal representation in one's mind based on the characteristics of the external object. For example, for a model of osmosis, I have a box that represents... two cells. I have a wall with holes that represents the cell membrane between the two cells and then there are different balls, smaller and bigger ones, where some can pass through and some cannot. (E6, 88-94).

...in Mendelian genetics, it is particularly hard for students to understand what the meaning of 'boxes' are with capital 'A' and small 'a', capital 'B' and small 'b' [...] That is a matter of translation, because you have a symbol and you ask them to translate the symbol back to... the chromosome. (E1, 274-278). 
The first quote above suggests that processing ER features requires interpreting how features of the ER are related to elements of the biological idea that is represented (e.g., Schönborn, Anderson, \& Grayson, 2002). Furthermore, the second quote suggests that interpreting an ER is challenging when pupils do not have the necessary biological knowledge.

Theme 5 Translation in biology requires moving across more than one ER that conveys the same biological idea

Four experts expressed the view that pupils will face learning situations where they are required to translate across more than only one ER that depicts the same biological idea. For example, consider the following expert quotes:

Translation... is very much related to building up a comprehensive understanding... by looking at an issue from different perspectives... using different representations because they have different strengths. If you talk about haemoglobin... you are referring to for example... a chemical formula which is one mode, then a three-dimensional [ER]... which adds another level of understanding. (E1, 317-324).

...they [students] learned how to make a drawing from this original picture [micrograph of plant cells containing chloroplasts]. And then, this is very important I think, [for students] to learn from this original picture, some principles, yes, and every example [of different micrographs of plant cells] shows another thing. This is very difficult for pupils. (E10, 85-89).

The first quote above indicates how different modes of representation may complement each other for harnessing a more complete understanding (e.g., Ainsworth, 1999). The second quote suggests that even the same ER mode (e.g., different micrographs) that represents the same idea (e.g., plant cell) can contribute to a more complete understanding. In turn, a single biological idea can present varying challenges to learners in that they depend on the types of ERs that are utilized (Schönborn \& Anderson, 2009).

Theme 6 Translation in biology requires moving across more than one ER that convey different biological ideas

Learning in biology also requires the interpretation of ERs that convey more than one biological idea. Here, learners are required to interpret ERs that each represent a different biological idea and thus, need to 'move across' each representation. Three experts mentioned that interpreting multiple ERs may involve moving across different biological ideas:

For example, talking about DNA and chromosomes... when dealing with this topic at the school level... showing what DNA looks like, you are just using symbols actually, because there is no other choice. So, for students, it is really difficult to, for example, differentiate between what DNA is and what chromosomes are. (E7, 1556-1560). 
...when looking at mitosis and meiosis, you have certain stages. And, for students it is very difficult $[\ldots]$ looking at the microscopic picture and comparing it to let's say, a figure in a textbook and seeing certain structures... organelles... (E7, 1461-1465).

Based on the data above, we suggest that knowledge acquisition and understanding can be fostered by supporting pupils' linking and integration of information from (multiple) ERs with existing knowledge, in order to develop a distinct understanding of different biological ideas (e.g., Ainsworth, 1999; du Plessis, Anderson \& Grayson, 2003).

What Knowledge is Necessary for Developing Biological Understanding at the Secondary Level?

In response to the second research question, document analysis of the German national biology education standards (KMK, 2005) and biology curriculum for Lower Saxony (Nds. Kultusministerium, 2007) resulted in the identification of four hierarchical types of biological knowledge (Figure 1). Consider the total collection of biological knowledge as analogous to a book and the following knowledge types as corresponding to the book's constituents.

\section{Type 1 Biological terms}

A biological term can be defined as conveying a limited fragment of biological knowledge (Figure 1). Arbitrary examples of biological terms could include antigen, antibody, enzyme, substrate, haemoglobin, alveoli, lungs, small intestine, villi, and microvilli. Each biological term captures a varying 'breadth' of factual knowledge. For instance, the biological term $D N A$ can be considered broad because it can be further divided into smaller elements of knowledge such as adenine and cytosine, while the biological term carbon may be considered a narrower term. In this respect, according to our definition, biological terms do not always convey equal 'units' of factual knowledge. Biological terms are the elements of biological meaning and are analogous with the 'words' of the biological knowledge 'book'.

\section{Type 2 Biological concept}

If the relationship between a group of biological terms conveys a common biological meaning (e.g., a biological process), then this relationship exists as a biological concept (Figure 1). Similar to a biological term, each biological concept can be thought of as existing on a 'broad' to 'narrow' continuum depending on the extent of the biological 


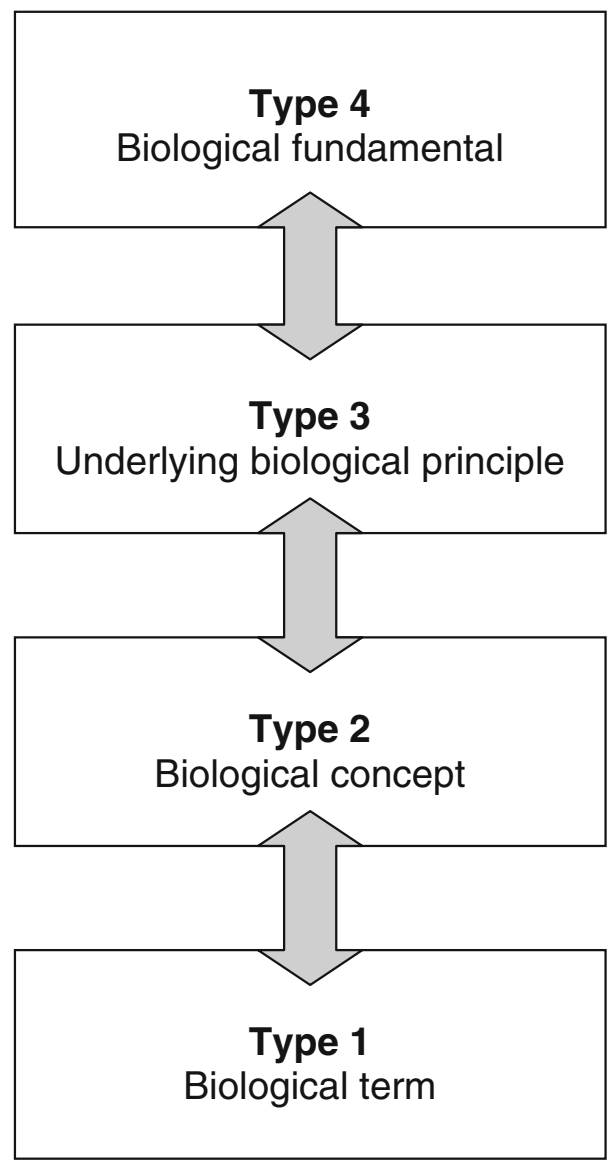

Figure 1. Four types of biological knowledge that pupils are required to develop at the secondary school level

meaning that is conveyed. For example, at the school level, the biological concepts human gaseous exchange and nutrient absorption in the human small intestine would be considered broad because many biological terms are required to communicate an extensive process. In contrast, the biological concepts antigen-antibody interaction and enzyme-substrate interaction are specific and require fewer terms for conveying narrower biological meanings. Analogously, biological concepts are the 'sentences' of the biological knowledge 'book'.

Type 3 Underlying biological principle

If a group of different biological concepts together communicate an underlying biological meaning common to the group, then such a relationship 
can be defined as a biological principle (cf. Nds. Kultusministerium, 2007) (Figure 1). Examples of biological principles could include those of increased surface area ('Prinzip der Oberflächenvergrößerung'), lock-and-key principle ('Schlüssel-Schloss-Prinzip'), cell theory ('Zelltheorie') and information paths in organisms ('Informationswege im Organismus'). Underlying biological principles can be considered analogous to the 'paragraphs' of the biological knowledge 'book'.

\section{Type 4 Biological fundamental}

If one underlying biological principle shares meaning with others, then together they contribute to a biological fundamental (Figure 1). Eight overarching 'Basiskonzepte" ${ }^{2}$ contained in the Niedersächsisches. Kultusministerium (2007) that (amongst others) include, compartmentalization, regulation and control and variability and adaptation, each serve as an example of a biological fundamental. The three overall 'Basiskonzepte' defined in the KMK (2005) document namely, system, structure and function, and development also each serve as an example of a biological fundamental (cf. Harms et al., 2004). For instance, the biological principles of cell theory and division of function, when considered together, can communicate an overarching meaning captured by the fundamental idea of compartmentalization. In completion of the analogy, biological fundamentals are the 'chapters' of the biological knowledge 'book'.

\section{How Might Transfer and Translation Processes Contribute to the Development and Application of Biological Knowledge?}

In response to the third research question, the six themes of expert responses identified in the interview data, and the different types of knowledge identified in the curriculum documents, were used as a combined data corpus for postulating the roles that transfer and translation play in the development and application of each type of biological knowledge.

Acquiring Knowledge About Biological Terms

Acquiring knowledge about biological terms does not depend solely on ER interpretation of course. Understanding verbal and numerical representations also play influential roles in developing type 1 knowledge (Figure 1). With respect to the interpretation of ERs, acquiring type 1 knowledge may occur during the interpretation of the different visual 
markings used in a single ER for depicting a specific biological term (e.g., antigen, substrate or alveoli).

Acquiring and Applying Knowledge About Biological Concepts

To construct understanding about a biological concept (type 2, Figure 1), learners may face the challenge of interpreting and linking ERs that all depict one specific biological concept. The ERs could depict the biological concept in the same or in varying modes of representation. Successful application of type 2 knowledge requires transferring knowledge about biological terms to the necessary biological concept that is being represented and vice-versa (bi-directional arrow in Figure 1), a process that may involve the translation across ERs. For example, these requirements are illustrated by four different possible learning situations provided in ESM\#1. Examples $A_{1}$ and $A_{2}$ require the transfer of elements of knowledge (cf. Hasselhorn \& Mähler, 2000) concerning a biological concept (enzyme-substrate interaction or antibody-antigen interaction) from one ER to another at the same level of biological organization. Scenarios $\mathrm{B}_{1}$ and $\mathrm{B}_{2}$ require integration of knowledge of a biological concept (nutrient absorption in the human small intestine or human gaseous exchange) by translating vertically between ERs at different levels of biological organization.

Acquiring and Applying Knowledge About Underlying Biological Principles

Constructing knowledge about an underlying biological principle (type 3, Figure 1) may involve interpreting ERs that each represent a different biological concept but together, depict one underlying principle. The ERs could convey the biological principle in the same or in different modes of representation. Successful transfer of type 3 knowledge requires the application of knowledge about biological concepts to knowledge of the underlying biological principle that is being depicted and vice-versa (bi-directional arrow in Figure 1). Four possible learning situations in ESM\#2 illustrate these requirements. Situations $A_{1}$ and $A_{2}$ require transfer of knowledge of an underlying biological principle (increased surface area or lock-and-key) from one ER to another by translating horizontally across ERs at the same level of biological organization. Examples $\mathrm{B}_{1}$ and $\mathrm{B}_{2}$ require the integration of knowledge of an underlying principle (cell theory or information paths in organisms) by translating vertically between ERs at different levels of biological organization. 
Acquiring and Applying Knowledge About Biological Fundamentals

Developing knowledge about a biological fundamental (type 4, Figure 1) may require learners to interpret ERs that represent different underlying biological principles that together, all communicate one biological fundamental. For example, understanding the idea of structure and function could occur through integration of knowledge about the lockand-key principle and the increased surface area principle. In another example, developing an understanding of compartmentalization could require the integration of knowledge about cell theory with the division of function principles. To perform such a transfer, pupils need to apply their knowledge and understanding of biological principles to their knowledge about the conveyed biological fundamental and vice-versa (bi-directional arrow in Figure 1). Illustrating the development and application of type 4 knowledge is not as concrete as for types 2 and 3 because a 'biological fundamental' is a more abstract and overarching construct. The acquisition of type 4 knowledge could rely more heavily on verbal discourse.

\section{DisCUSSION AND IMPLICATIONS}

This study has offered the following findings. Firstly, analysis of expert interviews delivered three themes concerning knowledge transfer and three themes concerning translation across ERs. Secondly, analysis of two relevant German curriculum documents uncovered four hierarchically organized types of biological knowledge that students are required to develop and apply during learning (Figure 1). Thirdly, we have framed relationships of transfer and translation processes with the acquisition of biological understanding.

With respect to research question 1, the expert themes may serve to highlight the challenges and complexities that learners face when it comes to transfer and translation processes in biology learning (cf. Hammann, 2006). In addition, the themes pertaining to vertical and horizontal transfer may complement and enhance the definitions that currently exist in the German curriculum literature. For example, our findings could be used to propose an intra-biological horizontal transfer, a specific premise that could extend current accounts that only refer to an inter-subject knowledge transfer. The experts' themes on translation across ERs could be viewed as a point of departure for explicitly defining the nature and goals of translation in biology teaching. Furthermore, our findings on 
experts' views about horizontal and vertical application of knowledge processes parallel aspects of recent research by Verhoeff, Waarlo and Boersma (2008). These researchers have provided evidence indicating that understanding cell biology is closely related to a 'systems thinking competence' fostered by an interaction with ERs, in order to promote the horizontal and vertical coherence of biological structures and processes. Similarly, our findings stress the significance of horizontal and vertical application of knowledge as part of fostering such 'systems thinking', a key feature of current German biology curriculum reform (Harms et al., 2004).

In response to research question 2, the four types of knowledge could provide a basis for conveying the overall structure of biological conceptual knowledge to teachers and learners alike. Type 1 knowledge may mirror the subcategories of the 'factual knowledge' category of Bloom's revised taxonomy defined as "knowledge of terminology" and "knowledge of specific details and elements" (Krathwohl 2002, p. 214). The natures of type 2, 3, and 4 knowledge are comparable to the 'conceptual knowledge' category of Bloom's revised taxonomy, which is defined as "the interrelationships among the basic elements [of factual knowledge] within a larger structure that enable them to function together" (Krathwohl, 2002, p. 214). Informing such parallels could also be useful for contrasting the identified knowledge types with other approaches in broader international biological contexts. For instance, the exposed knowledge types may complement work conducted by Khodor, Gould Halme \& Walker (2004), who have formulated a hierarchical biological concept framework that aims, in part, to illustrate which concepts are fundamental to biological understanding; how concepts can be broken down into subconcepts; how concepts are organized and, how concepts are related to one-another. Our own findings show that types 2, 3 , and 4 not only articulate hierarchically based knowledge but also reflect an increasing degree of abstraction. Although our knowledge types imply a hierarchical structure, we nevertheless suggest that the four types should not be regarded as stringent separate entities. For instance, it is difficult to define the exact boundary between where a 'biological term' ends and a 'biological concept' begins (e.g., DNA and human genome) or where a 'biological concept' ends and an 'underlying biological principle' begins. Elucidation of these knowledge types in a biology context also complements broader literature that has documented different types of knowledge (that include 'pictorial' qualities of knowledge) in a physics learning context (e.g., de Jong \& Ferguson-Hessler, 1996), as well as 
work that indicates how different types of knowledge can inform curriculum design (e.g., Carson, 2004).

With regard to research question 3, our interpretation of experts' themes in conjunction with the four types of knowledge demonstrates that knowledge transfer in biology requires the horizontal and vertical development and application of knowledge. Although our account aims to be as simplified as possible, transfer (and translation) operations necessary for acquiring each type of knowledge (Figure 1) will not always occur as straightforward linear bi-directional cognitive processes. For example, developing the biological concept, 'Nutrient absorption in the human small intestine' will not only involve moving 'linearly' across three ERs in the same mode at different levels of organization. A 'more complete' understanding could of course involve translating across other ER modes as well as cross-linking other elements of biological knowledge concerning absorption processes (e.g., Ainsworth, 1999; 2006) during additional concurrent horizontal and vertical cognitive processes. Expressing relationships between transfer and translation processes with the corresponding development of different knowledge types may also provide valuable contrasts with other work in biology education. For instance, Odom \& Kelly (2001) have suggested that relationships between the acquisition of declarative knowledge ('knowing that'), through the use of procedural knowledge ('knowing how'), can be useful for promoting biology learning. Our four types of knowledge could be considered synonymous with the 'declarative' aspect while transfer and translation processes could be equated with the 'procedural' aspect.

Given the research outcomes discussed above, our findings may be limited by the following. Firstly, since we relied exclusively on interview transcripts and documents as qualitative data sources, determination of experts' themes may have been influenced by our own interpretations of the data. Secondly, our constructed 'definitions' for transfer and translation presented at the commencement of each interview may have influenced experts into a particular way of thinking. A subsequent study would be useful in which follow-up questions are used to probe further for experts' secure opinions (e.g., Patton, 1990). On this score, a further study is also warranted to obtain experts' responses to any newly formed definitions that may emerge based on our present findings. Thirdly, due to the fact that responses were obtained from a limited number of participants, we may have unwittingly induced a systematic bias into the data. Nevertheless, we aimed to exclusively interview biology didactic role-players that, (i) were/are involved as experts in curriculum development and, (ii) had outstanding expertise in biology education 
research and knowledge about pedagogical psychology issues relevant to biology education. However, we found it difficult to identify many experts that had an exclusive knowledge about the roles of 'knowledge transfer' and 'translation' in biology education per se. Fourthly, although the interview audiotapes were transcribed verbatim and faithfully, we suggest that member checks of the interview transcripts (e.g., Lincoln \& Guba, 1985) may have strengthened the validity of the qualitative data by establishing further credibility of our categorization system. Fifthly, although our document analysis included the national education standards for biology in Germany, we only considered the biology curriculum for Lower Saxony. It remains to be seen how the curricula of other federal states align with the four knowledge types identified here. Hence, readers should be cautious when generalizing our results to broader biology education contexts.

Apart from the limitations above, our findings may shed light on the challenges that biology educators and learners face. Present curriculum reform in Germany aims to be a vehicle for learners' development of wellstructured knowledge, as well as to present opportunities for applying, connecting and cross-linking such knowledge (cf. BLK-expertise, 1997). Biology teachers face the task of: (i) promoting systematic knowledge acquisition within learners that reflects the structure of biological knowledge and its 'cross-linked' horizontal and vertical nature and, (ii) teaching to promote positive transfer (Hasselhorn \& Mähler, 2000). These prerequisites are also considered scientific competencies within the PISA framework (e.g., PISA-Konsortium, 2007), which could account for Finland and Canada's prominence as successful OECD countries. Finland's success could be due to a national programme that aimed, in part, to develop learners' and teachers' science knowledge and skills at all school levels (Välijärvi et al., 2002). Canada's 'Pan-Canadian Protocol for Collaboration on School Curriculum' emphasized knowledge and skills as two equally important foundations of scientific literacy (Council of Ministers of Education, 1995). With respect to the life sciences, the knowledge component highlighted understanding of concepts and principles with the goal to integrate and extend students' knowledge. The skill component emphasized the communication of scientific ideas and the application of scientific understanding to new situations. Hence, such a framework assists curriculum developers with formulating learning outcomes. Our identification of hierarchical types of biological knowledge and the illustrating of how application of such knowledge is related to transfer and translation processes, may contribute to assisting curriculum developers (e.g., Krajcik, McNeill \& Reiser, 2008), teacher trainers and teachers with fostering systematic and cross-linked 
knowledge within students. In conclusion, imparting the structure of biological knowledge together with transfer and translation processes will help achieve competency-based curriculum reform objectives.

\section{ACKNOWLEDGEMENTS}

We thank the experts for their kind participation, Rubina Irfan for useful discussions, and two anonymous referees for a valuable critique of earlier versions of this article.

OPEN ACCESS This article is distributed under the terms of the Creative Commons Attribution Noncommercial License which permits any noncommercial use, distribution, and reproduction in any medium, provided the original author(s) and source are credited.

\section{NOTES}

${ }^{1}$ All presented quotes are verbatim responses. Words between square brackets were inserted to improve readability and English fluency. An ellipsis within the text designates a sudden change in thought, pause, or denotes the exclusion of four words of transcript text or less. An ellipsis between square brackets designates the exclusion of five words or more. Each expert transcript was assigned a random identification ('E1' through 'E10'). The relevant expert and location of each datum in the original transcript text is indicated in brackets.

2 'Basiskonzepte' is used in the KMK (2005) and Nds. Kultusministerium (2007) documents to refer to the 'fundamental' components of biological content knowledge. The KMK document identifies three 'fundamental concepts' for the secondary I level. As part of standardized assessment requirements for university-entrance or 'Einheitliche Prüfungsanforderungen für des Abitur' (EPA), eight concepts have been identified for the secondary II level. The Nds. Kultusministerium document applies these eight EPA concepts to the secondary I level for improving subsequent systematic knowledge acquisition at the secondary II level.

\section{REFERENCES}

Ainsworth, S. (1999). The functions of multiple representations. Computers \& Education, 33(2-3), 131-152.

Ainsworth, S. (2006). DeFT: A conceptual framework for considering learning with multiple representations. Learning and Instruction, 16(3), 183-198.

BLK - expertise (Ed.) (1997). Gutachten zur Vorbereitung des Programms "Steigerung der Effizienz des mathematisch-naturwissenschaftlichen Unterrichts", Materialien, Heft 60. [http://sinus-transfer.uni-bayreuth.de-eft60.pdf] (accessed 17.06.2008). 
Carson, R. N. (2004). A taxonomy of knowledge types for use in curriculum design. Interchange, 35(1), 59-79.

Council of Ministers of Education (1995). Pan-Canadian Protocol for Collaboration on School Curriculum. [http://www.cmec.ca./science/framework/Pages/english/table.html] (accessed 18.06.2008).

de Jong, T., \& Ferguson-Hessler, M. G. M. (1996). Types and qualities of knowledge. Educational Psychologist, 31(2), 105-113.

du Plessis, L., Anderson, T. R., \& Grayson, D. J. (2003). Student difficulties with the use of arrow symbolism in biological diagrams. In J. Lewis, A. Magro, \& L. Simonneaux (Eds.), Biology education for the real world: Student-teacher-citizen (pp. 89-103). Toulouse: Ecole Nationale de Formation Agronomique.

Eigner-Thiel, S., \& Bögeholz, S. (2004). Bildung für Nachhaltige Entwicklung aus Sicht von MultiplikatorInnen außerschulischer Bildungsträger [Views of multipliers of extracurricular educational institutions regarding education for sustainable development]. Umweltpsychologie, 8(2), 80-100.

Erickson, F. (1986). Qualitative methods in research on teaching. In M. Wittrock (Ed.), Handbook of research on teaching (pp. 119-161, 3rd ed.). New York: Macmillan.

Glaser, B. G., \& Strauss, A. L. (1967). The discovery of grounded theory. Chicago: Aldine.

Hammann, M. (2006). Kompetenzförderung und Aufgabenentwicklung [Fostering competencies and development of competency-oriented tasks]. Der mathematische und naturwissenschaftliche Unterricht, 59(2), 85-95.

Harms, U., Mayer, J., Hammann, M., Bayrhuber, H., \& Kattmann, U. (2004). Kerncurriculum und Standards für den Biologieunterricht in der gymnasialen Oberstufe. In H.-E. Tenorth (Ed.), Kerncurriculum Oberstufe II - Biologie, Chemie, Physik, Geschichte, Politik. Weinheim: Beltz Verlag.

Hasselhorn, M., \& Mähler, C. (2000). Transfer: Theorien, Technologien und empirische Erfassung. In W. Hager (Ed.), Evaluation psychologischer Interventionsmaßnahmen: Standards und Kriterien: ein Handbuch (pp. 86-101). Bern: Verlag Hans Huber.

Häussler, P., \& Hoffmann, L. (2000). A curricular frame for physics education: Development, comparison with students' interests, and impact on students' achievement and self-concept. Science Education, 84(6), 689-705.

Khodor, J., Gould Halme, D., \& Walker, G. C. (2004). A hierarchical biology concept framework: A tool for course design. Cell Biology Education, 3(2), 111-121.

KMK (2005). Bildungsstandards im Fach Biologie für den Mittleren Schulabschluss. München: Wolters Kluwer.

Kozma, R. B., \& Russell, J. (1997). Multimedia and understanding: Expert and novice responses to different representations of chemical phenomena. Journal of Research in Science Teaching, 34(9), 949-968.

Krajcik, J., McNeill, K. L., \& Reiser, B. J. (2008). Learning-goals-driven design model: Developing curriculum materials that align with national standards and incorporate project-based pedagogy. Science Education, 92(1), 1-32.

Krathwohl, D. R. (2002). A revision of Bloom's taxonomy: An overview. Theory into Practice, 41(4), 212-218.

Lincoln, Y. S., \& Guba, E. G. (1985). Naturalistic inquiry. Newbury Park, CA: Sage.

Mayer, R. E. (2002). Rote versus meaningful learning. Theory into Practice, 41(4), 226-232.

Mayer, R. E. (2003). The promise of multimedia learning: Using the same instructional design methods across different media. Learning and Instruction, 13(2), 125-139. 
Mayer, R. E., \& Wittrock, M. C. (1996). Problem-solving transfer. In D.C. Berliner, \& R.C. Calfee (Eds.), Handbook of educational psychology (pp. 47-62). New York: Macmillan.

Mayring, P. (2000). Qualitative Inhatsanalyse: Grundlagen und Techniken (7th ed.). Weinheim: Deutscher Studien Verlag.

Miles, M. B., \& Huberman, A. M. (1994). Qualitative data analysis: an expanded sourcebook (2nd ed.). Thousand Oaks: SAGE.

Nds. (Niedersächsisches) Kultusministerium (2007). Kerncurriculum für das Gymnasium Schuljahrgänge 5-10: Naturwissenschaften, Biology. Hannover: Unidruck.

Odom, A. L., \& Kelly, P. V. (2001). Integrating concept mapping and the learning cycle to teach diffusion and osmosis concepts to high school biology students. Science Education, 85(6), 615-635.

Osborne, J., Collins, S., Ratcliffe, M., Millar, R., \& Duschl, R. (2003). What "ideas-aboutscience" should be taught in school science? A Delphi study of the expert community. Journal of Research in Science Teaching, 40(7), 692-720.

Patton, M. Q. (1990). Qualitative evaluation and research methods. Newbury Park, CA: Sage. PISA-Konsortium Deutschland (Ed.) (2005). PISA 2003: Der zweite Vergleich der Länder in Deutschland: was wissen und können Jugendliche? Münster: Waxmann.

PISA-Konsortium (Ed.) (2007). PISA 2006: Die Ergebnisse der dritten internationalen Vergleichsstudie. Münster: Waxmann.

Prain, V., \& Waldrip, B. (2006). An exploratory study of teachers' and students' use of multi-modal representations of concepts in primary science. International Journal of Science Education, 28(15), 1843-1866.

Rogers, M. P., Abell, S., Lannin, J., Wang, C.-Y., Musikul, K., Barker, D., \& Dingman, S. (2007). Effective professional development in science and mathematics education: Teachers' and facilitators' views. International Journal of Science and Mathematics Education, 5(3), 507-532.

Roth, W.-M. (2002). Reading graphs: Contributions to an integrative concept of literacy. Journal of Curriculum Studies, 34(1), 1-24.

Salomon, G., \& Perkins, D. N. (1989). Rocky roads to transfer: rethinking mechanisms of a neglected phenomenon. Educational Psychologist, 24(2), 113-142.

Schönborn, K. J., \& Anderson, T. R. (2009). A model of factors determining students' ability to interpret external representations in biochemistry. International Journal of Science Education, 31(2), 193-232.

Schönborn, K. J., Anderson, T. R., \& Grayson, D. J. (2002). Student difficulties with the interpretation of a textbook diagram of immunoglobulin $\mathrm{G}(\mathrm{IgG})$. Biochemistry and Molecular Biology Education, 30(2), 93-97.

Schreiner, C., \& Sjöberg, S. (2004). The Relevance of Science Education: Sowing the seeds of ROSE. Oslo: Acta Didactica.

Spiro, R. J., Collins, B. P., Thota, J. J., \& Feltovich, P. J. (2003). Cognitive flexibility theory: Hypermedia for complex learning, adaptive knowledge, application, and experience acceleration. Educational Technology, 43(5), 5-10.

Taylor, N., \& Corrigan, G. (2007). New South Wales primary school teachers' perceptions of the role of ICT in the primary science curriculum-a rural and regional perspective. International Journal of Science and Mathematics Education, 5(1), 85-109.

Tsui, C.-Y., \& Treagust, D. F. (2003). Genetics reasoning with multiple external representations. Research in Science Education, 33(1), 111-135.

Välijärvi, J., Linnakylä, P., Kupari, P., Reinikainen, P., \& Arffman, I. (2002). The Finnish success in PISA and some reasons behind it: PISA 2000. Jyväskylä: Kirjapaino Oma Oy. 
Verhoeff, R. P., Waarlo, A. J., \& Boersma, K. T. (2008). Systems modelling and the development of coherent understanding of cell biology. International Journal of Science Education, 30(4), 543-568.

Konrad J. Schönborn and Susanne Bögeholz

Didaktik der Biologie, Zentrum für empirische Unterrichts- und Schulforschung (ZeUS), Biologische Fakultät, Albrecht-von-Haller-Institut für Pflanzenwissenschaften

Georg-August-Universität Göttingen

Waldweg 26, 37073, Göttingen, Germany

E-mail:konsc@itn.liu.se

E-mail:sboegeh@gwdg.de

Konrad J. Schönborn

Division of Visual Information Technology and Applications (VITA), Department of Science and Technology (ITN)

Linköping University

Campus Norrköping SE-601 74, Norrköping, Sweden 